Published in: Yearbook of South Asian Languages and Linguistics 5 (2002), pp. 59-90 (ed. by R. Singh; New Delhi: Sage Publications)

\title{
SANSKRIT AS SHE HAS BEEN MISANALYZED PROSODICALLY
}

\author{
Richard D. Janda \& Brian D. Joseph \\ The Ohio State University
}

\author{
Address of authors: \\ Department of Linguistics \\ 222 Oxley Hall \\ The Ohio State University \\ Columbus, Ohio USA 43210-1298
}

Phone: 1-614-292-4052

Fax: 1-614-292-8833

e-mail: bjoseph@ling.ohio-state.edu // rjanda@ling.ohio-state.edu 
SANSKRIT AS SHE HAS BEEN MISANALYZED PROSODICALLY 
Abstract

The various alternations between aspirated and unaspirated segments in Sanskrit phonology that have come to be discussed under the rubric of Grassmann's Law and Bartholomae's Law and their interaction have long been a stumbling block as well as a proving ground for various phonological theories. In this paper we give a detailed critique of analyses of these phenomena within a 'Late Classical' autosegmental framework (circa mid-to-late 1980s) which have not been challenged in the literature even with the major changes in theory heralded by Feature Geometry and Optimality Theory. While updating our critique to encompass these further advances in phonological theory, we find no purely phonological account to be satisfactory, and thus argue that the key to understanding these Sanskrit aspiration alternations lies in recognizing the essentially morpholexical nature of the relevant phenomena. Accordingly, we provide a sketch of an account within a Process Morphology framework, in the spirit of the analysis given by Pán $\geq$ ini nearly 2500 years ago. 


\section{Introduction}

The title of this paper deserves some explanation. It is inspired by a brief anonymous note published in the Indian periodical, Indian Linguistics (42 (1981), p. 81) and entitled 'Sanskrit as she is spoke at M.I.T. Press'. In it, attention was drawn - with playful intent, we believe — to a textbook in historical linguistics (Jeffers \& Lehiste 1979) in which some example sentences were constructed using Sanskrit verbs but English noun-forms; these sentences thus did not represent Sanskrit in any real sense, being at odds with the actual facts of the language, e.g., regarding case-marking. ${ }^{1}$

In this paper, focusing not on M.I.T. Press but rather on the M.I.T. linguistic tradition, we question some generative linguistic descriptions and analyses of Sanskrit which we feel are at odds with the actual facts of the language. In particular, we subject to severe criticism - all of it, we believe, justified - two treatments of Sanskrit aspirationrelated alternations. These alternations derive historically from the interaction of Grassmann's Law ${ }^{2}$ with other sound changes, including Bartholomae's Law (discussed at some length below), and are often seen as involving an 'Aspiration Throwback' effect; compare, e.g. bodh-ati '(s)he knows' and bhot-sya-ti '(s)he will know'. The two analyses on which we focus, Borowsky \& Mester 1983 (hereafter B\&M) and Kaye \& Lowenstamm 1985 (hereafter K\&L), adopt an Aspiration Throwback approach (as have virtually all works since Sag 1976 and Schindler 1976; cf. Janda \& Joseph 1988a), but most importantly they treat the phenomenon as being purely phonological in nature. By contrast, we provide an alternative morphological analysis, already foreshadowed in spirit by Sag 1976 and consistent (as Sag himself explicitly notes) with the essentially ProcessMorphological treatment of Pán $\geq i n i$ from 2500 years ago.

Given that the two accounts in question appeared in the mid-1980s and therefore predate many theoretical developments that have characterized phonological theory in the intervening 16 years - not only Optimality Theory but also Feature Geometry, for 
instance - it might be thought that, in discussing these, we are beating a dead horse into the ground (so to speak). However, this is in fact not the case; we are not beating a dead horse but defending a dead language.

In the first place, with only one exception - Broe 1991, who does not discuss either $\mathrm{B} \& \mathrm{M}$ or $\mathrm{K} \& \mathrm{~L}^{3}$ - we do not know of any more recent published treatments focusing primarily or even in passing, on the above-mentioned Sanskrit facts. Instead the recent literature on aspiration in Sanskrit is made up of surprisingly brief references on the order of the following taken from Kenstowicz 1993:

[+spread gl[ottis]] ... may delink from one position and surface elsewhere (e.g. Grassmann's Law in Sanskrit) [p. 493]

[an] unlicensed laryngeal feature ... may delete or relink at some adjacent position (e.g., the aspiration throwback of Grassmann's Law) [p. 495]

Such short-cuts (to phrase matters generously) show a cavalier disregard for both the terminology and the content associated with discussions of Grassmann's Law in the specialist literature within Indo-European, Indo-Iranian, and Indic historical linguistics indeed, but even within generative phonology itself. The source of such an error is not far to seek: many articles have discussed the two distinct but related phenomena of Grassmann's Law and Aspiration Throwback in the same breath, as it were.

Moreover, within a single widely cited volume, the Handbook of Phonological Theory, edited by John Goldsmith (1995), Sanskrit phonological and morphological phenomena have been misleadingly presented. For instance, Steriade (1995: 149) states it as a known fact that 'only one aspirated stop is allowed within a given root in IndoEuropean, Sanskrit, and Greek'. While diaspirate roots are admittedly rare, and possibly late, in the Sanskrit tradition, they do exist in the language; examples include $\sqrt{\text { dhrákh- }}$

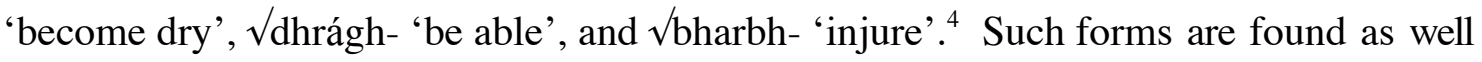


occasionally even in Greek (e.g., thuphlós 'blind', a dialect variant of the more widely attested tuphlós). ${ }^{5}$

Further, McCarthy \& Prince (1995: 365n.8) suggest, albeit somewhat tentatively, that 'apparently, complex onsets ... in Sanskrit ... [are absent from] all affixes, ... not just reduplicative ones'. Appearances, however, can be deceiving, given that there are complex onsets not only in (somewhat lexical, i.e., content) prefixes such as pra- 'before' and prati- 'against, in return, towards' but also in such grammatical suffixes as the 2PL.Non-Active ending -dhve, tbe gerund ending -tvá, etc. - all with complex onsets of obstruent plus sonorant.

On the other hand, the admittedly brief further statements that relate directly or indirectly to Sanskrit aspiration in a number of other papers in Goldsmith 1995 are accurate. Three of them bear only minimally on the matter at hand: Clements \& Hume (1995: 269), Kiparsky (1995: 661), and Ohala (1995: 714). A fourth, moreover Blevins (1995) - is not only right on target as regards the facts but furthermore absolutely consistent with the major thesis defended below: namely that Sanskrit aspiration alternations demand a treatment within morphology (and not just via some 'morphologically conditioned phonological rule', whatever that might be - see Janda 1987). That is, Blevins explicitly recognizes that '...[c] onstraints on aspiration in Sanskrit hold within the morphological stem' (p.235n.8). ${ }^{6}$

Before we proceed to the details of the analyses and of our counter-analysis, a word on notation and theoretical orientation is in order. Both B\&M and K\&L operate within what might be called a 'Late Classical' autosegmental framework, one heavily influenced by McCarthy $(1979,1981)$ An aspiration feature, represented as $H$, constitutes an autosegment which is (or can be) linked to a C-position on a skeletal template (sometimes unsystematically represented as a direct association with a phonemic-melodic element such as $/ \mathrm{b} /$ or $/ \mathrm{p} /$ ) or to another autosegment (we illustrate their practice more explicitly 
below). However, in the same year as K\&L's paper, Clements 1985 appeared - a highly influential paper that did much to establish the current geometrical approach to feature structure. Later still, McCarthy \& Prince 1986 pioneered the less segmental and more mora-, syllable-, and foot-based approach known as Prosodic Morphology. While we briefly sketch below what the feature geometric equivalent of B\&M and K\&L's earlier autosegmental analyses would be, we retain their original notation for most purposes, mainly for ease of exposition, but also because it seemed inappropriate to claim to have refuted an analysis which was recast entirely by us rather than by the original authors. In parallel fashion, B\&M and K\&L obviously predate by nearly a decade the rise and spread of Optimality Theory (OT; see, e.g., Prince \& Smolensky 1993). Although in this case we provide some discussion of our analysis in OT terms, we again — for precisely the reasons just mentioned - eschew the exercise of converting their analysis into an Optimality Theoretic one. Furthermore, we would like to call attention here to the fact that OT is a much more congenial home for Process Morphological analyses than was the pre-OT scene, since, e.g., it gives no particular credit for - and sees no theoretical advantage to - the positing of floating autosegments which require intermediate derivational steps. Nevertheless, none of our arguments hinge on these analytical and expositional decisions.

Let us note here, though, that there is an unfortunate tradition, in generative accounts of Sanskrit, of understating the range of facts that need to be taken into consideration in accounts of particular phenomena (on reduplication, for example, see Janda \& Joseph 1986). ${ }^{7}$ Not wishing to fall into this practice, we begin our exposition by pointing out, as most researchers in fact do realize, that actually there is more allomorphy in the aspiration throwback roots than just budh-/bhut-; there is also an allomorph bud-. We illustrate all these more fully in (1), continuing to use the root budh- as our examplar:

(1) 3SG.PRES.INDIC.ACT bodh-ati '(s)he knows' 


\section{SG.AOR.INDIC.MID a-bhut-s-i 'I knew' \\ 3SG.FUT.INDIC.ACT bhot-syati '(s)he will know' \\ PST.PASS.PARTCPL bud-dha- '(having been) known'.}

Descriptively, these alternations involve the transfer of aspiration between the two consonants in the root, though aspiration never occurs overtly on both, as well as the transfer of aspiration to a nonroot segment.

The relevant allomorphs of such roots - i.e. the actual forms that an adequate grammar of Sanskrit must somehow account for, are listed in (2) - with the form of the vocalic nucleus abstracted to $\mathrm{V}$ :

$$
\text { bVdh- bhVt- bVd-. }
$$

As is easily imaginable from our introductory discussion, alternations such as these have long been a stumbling block, as well as a proving ground, for phonological theories within generative phonology, starting as early as Kiparsky 1965 and Zwicky 1965. Thus it is no surprise that, just barely after the dust had settled from reconsiderations of this controversy within the framework of 'Late Classical' (or 'Middle High') generative phonology, in the early-to-mid 1970's (represented, for example, by Sag 1974, Hoard 1975, Phelps 1975, Sag 1976, Schindler 1976), a recasting of the problem in the nonlinear framework of autosegmental phonology was soon undertaken. Stemberger 1980 was the first such treatment, followed in elaborated form by B\&M, with further refinements offered soon thereafter by K\&L (we have already mentioned the revisions in notation, but not content, later made available by feature geometry, Prosodic Morphology, and OT).

These alternations would seem, at first glance, to be exactly the sort of phenomenon that autosegments were invented for, so to speak, inasmuch as there is an element, aspiration, that appears in different but nearby locations. Thus, the two main autosegmental treatments, $\mathrm{B} \& \mathrm{M}$ and $\mathrm{K} \& \mathrm{~L}$, along with the further analytical steps that they entail are the focus of our attention here, because we feel that, in spite of some 
initially attractive features, their analysis proves, on close inspection, simply to be untenable. Despite the fact that these accounts were proposed several years ago, the bases of the autosegmental analysis have not, to the best of our knowledge, been challenged in the literature, nor have many crucial details on which both $\mathrm{B} \& \mathrm{M}$ and $\mathrm{K} \& \mathrm{~L}$ err been brought to light, all this despite the fact that certain aspects of the analysis are beset from the start by serious problems. Thus, here - besides clearing up several errors of fact in these treatments - we offer a rebuttal to the key features of the autosgemental phonological analysis of the Sanskrit aspiration alternations.

\section{The Borowsky \& Mester/Kaye \& Lowenstamm Analyses}

We first give an overview of B\&M's and K\&L's autosegmental analyses, for the benefit of readers who (through no fault of their own) may not be intimately acquainted with them.

Following what has become standard terminology in discussions of these alternations (as alluded to above in our introduction), we refer to the presence of initial aspiration in a root in the absence of root-final aspiration - as e.g., in the future stem bhot-sya-, from (1) above - as the 'aspiration throwback' effect.

$\mathrm{B} \& \mathrm{M}$ and $\mathrm{K} \& \mathrm{~L}$ attempt to explain the aspiration throwback effect in purely autosegmental phonological terms, and to account at the same time for the absence of the Aspiration Throwback effect in other related forms - as, e.g., in the past passive participle buddha-, also from (1). The basic approach taken is to treat aspiration throwback and related phenomena as an inherently phonologically conditioned set of processes; the fundamental aspects of their analysis are summarized in what follows.

First, the autosegmentalists assume that the aspiration which is found with the voiced stops (e.g., dh) is to be distinguished from the aspiration that is found with the voiceless stops (e.g., th). This distinction between what can be called 'voiceless 
aspiration' and 'voiced aspiration' can be encoded in Sanskrit grammar in a number of ways; the approach suggested by B\&M is to assign the same feature (their ' $[+\mathrm{H}]$ ') to one place (one autosegmental level) in the internal structure of the feature complex for voiced stops but to a different place for voiceless stops. Moreover, they assume that only voiced stops can be associated with the type of aspiration that is found with voiced stops. $\mathrm{K} \& \mathrm{~L}$ achieve this result by linking aspiration $(\mathrm{H})$ to a voicing autosegment (their ' $\mathrm{Z}$ '), thus essentially differentiating between voiced aspiration and voiceless aspiration, in the sense that voiceless aspiration is neither autosegmentally realized nor linked to a voicing autosegment, as is voiced aspiration.

Thus for B\&M, the Sanskrit bilabial voiced aspirate stop bh (so described also in traditional terms) bh is represented as in (4a); for $\mathrm{K} \& \mathrm{~L}$, the relevant representation is as in (4b), for which one updated feature geometric version would be (4c):

(4) $\mathrm{a}$

$$
\mathrm{H}
$$$$
\text { । }
$$

/b/ b.

$\mathrm{H}$

I

$\mathrm{Z}$

I

$$
/ \mathrm{p} /
$$

c.

root

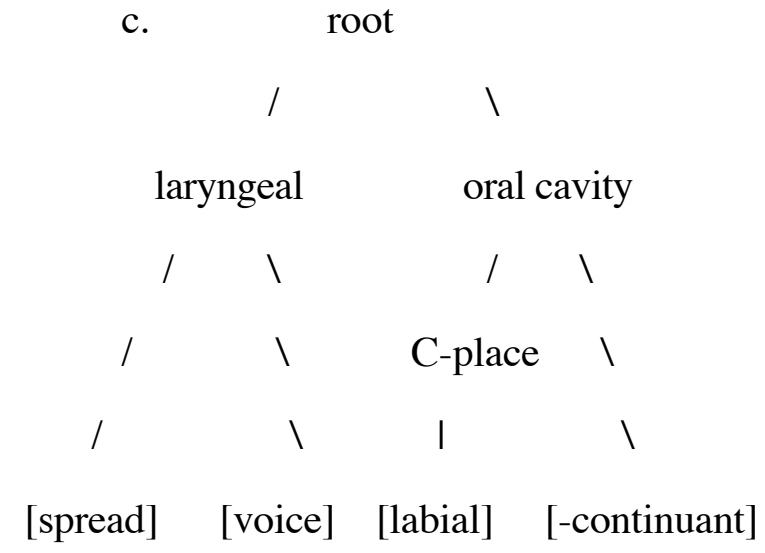

Second, a further claim emerges, in B\&M's and K\&L's view, from their decision to represent the voiced aspirates (e.g., $\underline{\text { dh }}$ ) with autosegmental aspiration - i.e., as an element on a different phonological level (or tier) from the segmental melody - and from their assumption that only voiced stops can be bearers of 'voiced aspiration'. In particular, when devoicing occurs somewhere in a root (as with the root-final element in the future bhotsyati), the aspiration autosegment must be disassociated from the devoiced stop, and this newly 'liberated' aspiration autosegment must reassociate with an 
acceptable bearer - in this case, the root-initial element, which is acceptable because it is a voiced stop. ${ }^{8}$ A sample derivation is given in (5) for the future bhotsyati (with some nonessential details ignored):

$\mathrm{H}$

।
$\mathrm{H}$

$\mathrm{H}$

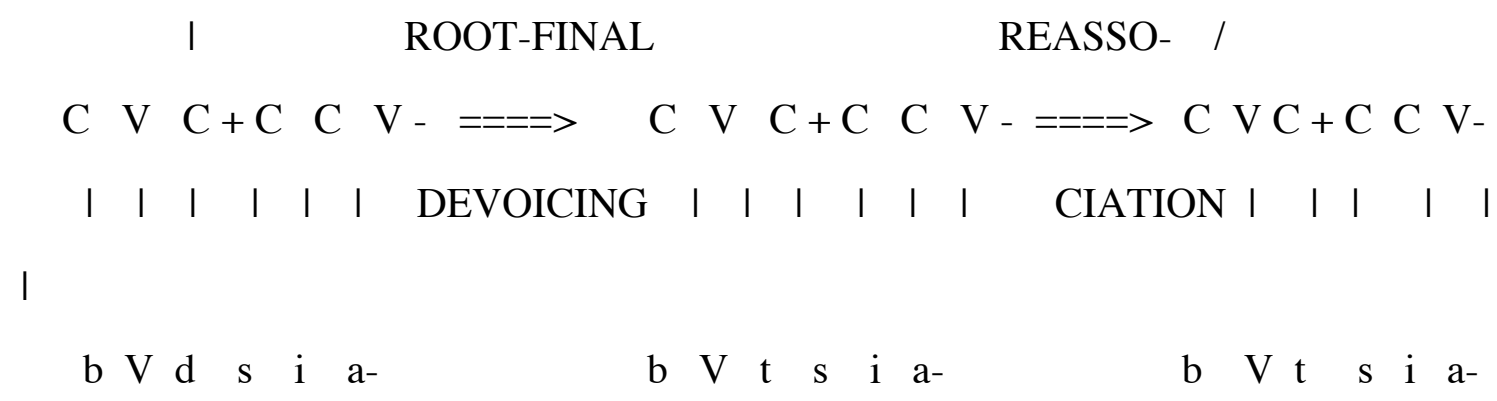

The difference between their representation of voiced aspirates versus voiceless aspirates is utilized by $\mathrm{B} \& \mathrm{M}$ to account for the difference between the aspiration throwback effect in bhotsyati and what they claim to be the lack of such aspiration throwback in a root which ends in a voiceless aspirate and has a voiceless stop elsewhere in the root as the potential bearer of the aspiration autosegment. Such a root is $\sqrt{ }$ prach'ask', ${ }^{9}$ which shows the future stem praksya-, and not *phraksya-. Thus, there is no aspiration throwback effect with $\sqrt{ }$ prach-. This fact is explained, according to B\&M, as resulting from the fact that the root-final voiceless aspirate does not have the $[+\mathrm{H}]$ aspiration autosegment, aspiration on voiceless stops instead being a feature of the

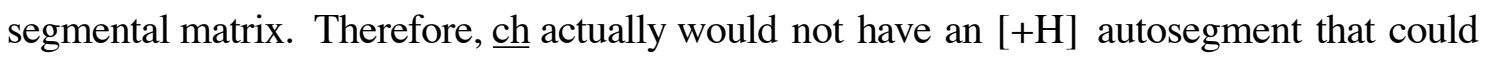
be liberated and so be in need of reassociation. Thus, segemental deaspiration would occur, but no throwback would be possible, inasmuch as it depends on autosegmental aspiration. ${ }^{10} \mathrm{~K} \& \mathrm{~L}$ are silent on this matter, but given their general approach, it can be assumed that they would basically follow B\&M here. In feature-geometric terms, one can simply write the relevant delinking/relinking rules for Sanskrit to operate on a glottal/laryngeal node only if it dominates both [spread gl(ottis)] and [voice], rather than [spread gl] alone. 
Third, something must be done in an autosegmental analysis - or any framework, for that matter - with the -DDH- clusters that arise in forms such as the past passive participle buddha- - i.e., the Bartholomae's Law phenomenon. B\&M analyze the DDh- cluster in buddha- (and those similar ones in other forms) as being aspirated throughout: i.e., as being phonetically [bud $\left.\mathrm{h}_{\mathrm{d}} \mathrm{h}_{\mathrm{a}-}\right]$. Bartholomae's Law (BRTHLAW below) is thus treated as a progressive voicing assimilation process with no deaspiration, but rather with aspiration spreading. This step then obviates the need for aspiration throwback since in their terms there is no deaspiration of the root final segment, and thus no liberated autosegmental aspiration in need of reassociation. This aspect of the analysis is shown in (6).

$$
\begin{aligned}
& \mathrm{H} \quad \mathrm{H} \\
& \text { BRTH I । } \\
& \text { C } \mathrm{V} \quad \mathrm{C}+\mathrm{C} \quad \mathrm{V}-=====>\quad \mathrm{C} \quad \mathrm{V} \quad \mathrm{C}+\mathrm{C} \mathrm{V}-
\end{aligned}
$$

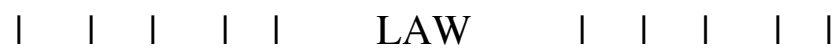

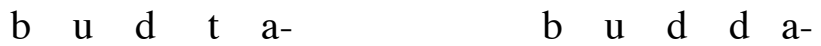

$$
\begin{aligned}
& \left(=\left[\text { bud }_{\mathrm{d}} \mathrm{h}_{\mathrm{a}-}\right]\right. \text {, graphic <buddha->). }
\end{aligned}
$$

$\mathrm{K} \& \mathrm{~L}$, on the other hand, utilize a notion of syllabic prominence, a device originally employed mainly for accentual phenomena, and assume that aspiration, like accent in some languages, can reassociate only with nonrecessive (i.e. strong) positions in a syllable - e.g., the syllable onset, but not the syllable coda. Thus for them, the cluster -ddh- need not be aspirated on both segments but instead need only be assumed to have the first element in one syllable as the coda and the second element in another syllable as an onset; only the second segment in the cluster would then be 'strong' and thus capable of bearing aspiration.

Conveniently, Kenstrowicz (1993: 160-161) provides an explicit feature-geometric formulation of Bartholomae's Law, which we cite at length below: 
A common form of reduction is the suppression of laryngeal distinctions in the coda of the syllable. For example, many languages oppose plain, aspirated, and voiced stops [p, b, $\mathrm{p}^{\mathrm{h}}$ ] in syllable onsets but limit their coda to just $[\mathrm{p}]$... Other laryngeal features sometimes display similar behavior. A possible example is Bartholomae's Law in the development of Sanskrit, where an Indo-European $[\mathrm{bh}+\mathrm{t}]$ cluster is realized as $[\mathrm{b}+\mathrm{dh}]$, with the apparent transfer of voicing and aspiration from the coda [bh] to the following onset $[\mathrm{t}]$... Under the earlier theory in which features form an unorganized bundle, this sound change requires a simultaneous modification of the coefficients of both [spread gl] and [voiced] at two successive positions in the cluster (22a).

(22) a. [+spread gl] [-spread gl] $\rightarrow$ [-spread gl] [+spread gl] [ +voiced ] [ -voiced ] [ +voiced ] [ +voiced ] $\left[\begin{array}{llll}\left.\mathrm{b}^{\mathrm{h}}\right] & {[\mathrm{t}]} & {[\mathrm{b}]} & {\left[\mathrm{d}^{\mathrm{h}}\right]}\end{array}\right.$
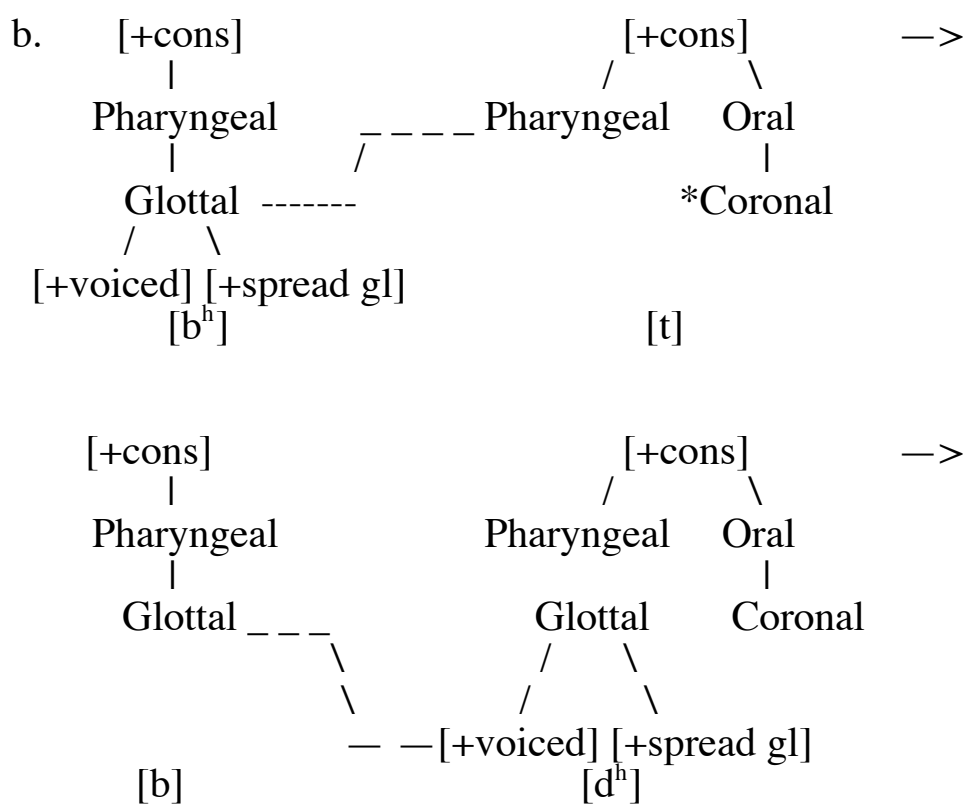

But, given the Articulator Model, it can be described as the delinking and subsequent relinking of the Glottal articulator. 
We note that Kenstowicz too, like us, analyzes the cluster that results from this rule as having only final aspiration, not aspiration on both members.

Fourth and finally, as has been frequently observed (so Sag 1974, 1976, Schindler 1976, and others), reduplication syllables in Sanskrit generally do not tolerate aspiration. ${ }^{11}$ B\&M block the reassociation of a floating aspiration autosegment with a reduplication syllable via a brute-force stipulation - e.g., through prespecification of reduplication template as tolerating only nonaspirated consonants - and thus 'explain', after a fashion, the absence of aspiration in (most) reduplicative affixes. K\&L, on the other hand, have nothing to say about this particular deaspiration phenomenon. ${ }^{12}$

As noted above, the B\&M approach has not been seriously challenged in the literature, though K\&L offered some early refinements. We therefore here present a rebuttal of their autosegmental arguments in favor or purely phonological analyses for Sanskrit aspiration throwback. In particular, we furnish counterevidence to each of the main points of B\&M's analysis as summarized above, and of K\&L's where appropriate, especially where the two analyses differ. Taken together, these counterarguments have the effect of demonstrating that the autosegmental approach to aspiration throwback (and any other possible recasting thereof in a similar vein) is not only poorly motivated in the absolute but also distinctly inferior to a morphological account. More generally, we argue that the basic problem with $\mathrm{B} \& \mathrm{M} / \mathrm{K} \& \mathrm{~L}$-type approaches is that they take a lexically restricted process (about which more later) — one with various morphological conditions on it (e.g., that aspiration is absent from reduplication in most morpholexical categories) - and try to turn it into pure phonology. Finally, we present the outlines of an analysis, framed within a Process Morphology model, in which not everything that affects the phonological shape of a morpheme must be carried out in the phonological component or by phonological rules. 


\section{Contra Autosegmental Accounts of Aspiration Throwback}

We turn now to a point-by-point consideration of B\&M's and K\&L's analyses though, for expository reasons, we do so in a different order from the presentation of their arguments above.

\subsection{Regarding Voiced Aspiration as an Autosegment}

First, with regard to the claim that voiced aspiration should be treated as an autosegment (or alternatively, as a unitarily de-/re-linking feature geometric node), it must be admitted that this certainly is an initially plausible analysis. Nevertheless, there is no independent evidence for such a treatment, however attractive it might be on theoretical grounds - especially given that both of B\&M's arguments in support of this view turn out to be nonarguments. K\&L offer no additional arguments; they instead merely assume B\&M's position.

B\&M point to alternations and/or alternatives involving voiced aspirates and the Sanskrit consonant $/ \mathrm{h} / \mathrm{-}$ see (7) - as evidence that aspiration is an autosegment, since they reason (p. 53) that in these, 'the [segmental] melody may be deleted [but] the aspiration is unaffected':

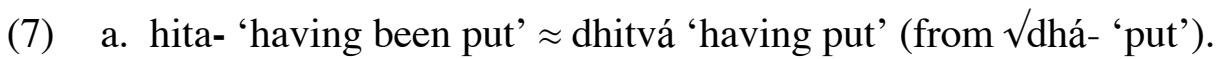

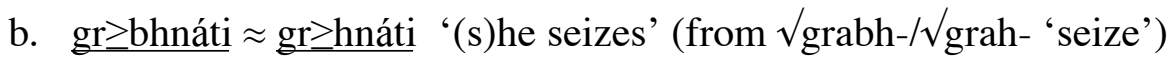

Such facts might seem to give an autosegmental treatment a clear advantage over alternatives, since earlier, segmental, approaches which treat [aspiration] as just one element in a feature matrix appear to require considerable power in paring down such a matrix from $\underline{\mathrm{bh}}$ or $\underline{\mathrm{dh}}$ to just $\underline{\mathrm{h}}$. That is, though perhaps not impossible, such a tactic of differential feature-matrix shakedown (as it were) is difficult to reconcile with usual assumptions about the writing of rules and about reference to features in such rules. Still, while autosegmental aspiration might initially seem to simplify such matters, the situation is far more complicated than B\&M let on. 
In particular, the decision to derive, in forms such as those in (7), the Sanskrit aspirate $\underline{h}$ (usually described as a voiced - probably murmured - glottal continuant; cf. Whitney 1889: $§ 65$ for discussion) by conversion from an obstruent (even an aspirated one) runs into the same problems encountered by feature-geometrical (née autosegmental) treatments of the so-called 'aspiration' of /s/ in Andalusian as well as many New World varieties of Spanish. In both of these, the crucial requirement for an elegant account is that the conversion in question be effected by a single unitary localized operation on feature structure; in the words of s Kenstowicz (1993: 159): 'many researchers have viewed such sound changes as ... [s] to [h] ... as a suppression of the supraglottal articulation ... [but] the status of [continuant] in these changes is controversial'. Since Sanskrit $\underline{\mathrm{dh}}$ and $\underline{\mathrm{bh}}$ are [-continuant], whereas $\underline{\mathrm{h}}$ has been treated as [+continuant], Kenstowicz's remarks about Spanish apply here as well: i.e., it may take two or more operations to carve $\underline{\mathrm{dh}} / \underline{\mathrm{bh}}$ down to $\underline{\mathrm{h}}$, thus potentially nullifying any other advantages of the autosegmental approach.

B\&M's second argument has to do with the fact that, as noted above, aspiration virtually never occurs in reduplicated syllables, i.e., with the fact that, in their terms, the segmental melody can be copied in reduplication independently of aspiration, as in (8):

(8) a. ل Vhá- 'put' $\rightarrow$ present stem da-dhá-

b. ' bhí- 'fear' $\rightarrow>$ aorist stem bi-bhay-a-.

However, B\&M themselves recognize that there is a need for prespecification of the reduplicated syllable (what might now be recast as melodic overwriting, cf. McCarthy), at least for the change of velars to palatals as a regular part of reduplication; see(9):

(9) a. $\sqrt{ } \mathrm{kr}$ - 'make' $\rightarrow$ perfect stem ca-kar-

b. ل Vá- 'go' $\rightarrow$ present stem ji-gá-.

In actuality, then, a further prespecification (or overwriting) for [-aspirate] is hardly an added burden on the grammar of Sanskrit, since some prespecification is already 
independently necessary, and hence independently motivated, for the velar-to-palatal part of reduplication. Curiously, B\&M also realize (p.62n.5) that accepting prespecification vitiates their 'argument from reduplication for the independence of the autosegmental $\mathrm{H}$ from the segmental melody', but they add - somewhat plaintively, it seems to us - that 'this is not devastating since ... there is enough independent support for our analysis'. In view of our overall remarks here, however, this last statement of theirs is seriously open to question.

\subsection{On the Unity of Voiced Aspiration and Voiceless Aspiration}

The next major part of the autosegmental analysis is the claim that, in phonological representations, voiced aspiration is to be distinguished from voiceless aspiration. Here again, we argue that the autosegmental analysis is on shaky ground. ${ }^{13}$

First, as concerns the phonetics of the aspiration in the so-called 'voiced aspirates' versus that in the voiceless aspirates, it is not entirely clear just how different the two types are. It is of course true - as both Allen 1953 and Bare 1980 have pointed out in their surveys of the statements made regarding these sounds in the prátisvákhyas (the native Sanskrit grammatical treatises dealing with phonetics) - that there are some differences in the descriptions of these two sorts of sounds. Allen observes that 'the voiced aspirates are considered as more fully voiced than the non-aspirates, and the voiceless aspirates more fully breathed than the non-aspirates'. It is also true that writings by some phoneticians - e.g., Ladefoged 1975 - have claimed that the so-called 'voiced aspirates' are actually breathy voiced, or murmured, consonants. However, Allen 1953 himself ends up adopting the view that the differences between the two types of stops are not significant with regard to aspiration, and he speaks of $\underline{\mathrm{bh}}, \underline{\mathrm{dh}}$, etc. as legitimate voiced aspirated stops. Bare's consensus overview of the various prátisvákhyas reaches a similar position.

Moreover, despite Ladefoged's early (1975) view, it is significant that in subsequent works he later recanted (so to speak); cf. Ladefoged 1982, 1993: 144-146.. In any case, 
there are studies, such as that of Benguerel \& Bhatia 1980, which show that it is indeed not improper to speak of 'voiced aspirates' (even if the term is phonetically a bit misleading). This is especially so if - following Ladefoged 1976 - one defines aspiration in a somewhat general way as 'a period after the release of a stricture and before the start of regular voicing in which the vocal cords are further apart than they are in regularly voiced sounds', or - like Dixit 1979 - as 'glottal friction produced with or without pulsing while the glottis is narrowly or widely open and the supraglottal vocal tract is unobstructed'. Thus the phonetic evidence is somewhat ambiguous, but it leans towards favoring a unified treatment of voiced and voiceless aspiration. ${ }^{14}$

Second, from a phonological standpoint, there is no reason to distinguish th (etc.) from $\underline{\mathrm{dh}}$ (etc.) vis-à-vis aspiration, because they show parallel phonological behavior synchronically and diachronically - when they undergo various processes which involve aspiration. For example, both voiceless aspirates and voiced aspirates deaspirate when reduplicated, as shown in (10):

(10) a. V'bhid- 'split' $\rightarrow>$ perfect stem bi-bhed-, desiderative stem bi-bhit-sa-

b. Vphar- 'scatter' $\rightarrow$ intensive stem par-phara-

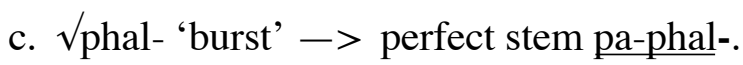

And, further relevant forms bearing on the matter at hand are shown in (11):

(11) a. samidh- 'wood, fuel' $\rightarrow$ samit (NOM.SG)

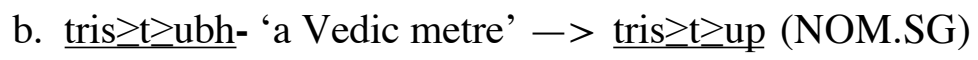

c. $\underline{\text { kapr } \geq \text { th- 'penis' } \rightarrow \text { kapr } \geq t}$ (NOM.SG)

Here, both voiceless and voiced aspirates can be seen to deaspirate in word-final or rootfinal position, though examples with voiceless aspirates seem to be restricted to a single lexical item, kapr $\geq$ th- 'penis'. ${ }^{15}$ One other deaspiration context in which the voiced and voiceless aspirates behave alike comes from the automatic doubling of a consonant after $\mathbf{r}$ (and in some other contexts; see Vaux 1992). Thus, e.g., arka- 'light' is realized as 
[arkka-], and when an aspirate, whether voiced or voiceless, is so doubled, aspiration is found only on the final (rightmost) member of the doubling; e.g., we find artha- 'goal' $\rightarrow$ [arttha-] (not *[arththa-]), dírgha- 'long' $\rightarrow$ [dírggha-] (not *[dírghgha-]), etc.

Third, from a diachronic standpoint, both voiceless aspirates and voiced aspirates in nonreduplicated syllables not only deaspirated via Grassmann's Law but also triggered deaspiration via Grassmann's Law; the two examples shown in (12) attest to their parallel historical behavior in this regard:

(12) a. vidatha- 'distribution' < *vi-dh-atha- (cf. vi + ل dhá- 'distribute')

b. kumbha- 'pot' < *khumbha- (cf. Avestan xumba-).

Fourth, the conclusion that there is a close relationship between the voiceless and the voiced aspirates is suggested by the fact that a voiceless aspirate becomes a voiced aspirate when it is in a position where it can undergo voicing assimilation - in particular, in a Bartholomae's Law context: one involving a preceding voiced aspirate, where progressive voicing assimilation is the norm. ${ }^{16}$ Thus, the second person singular middle-voice past ending -thás, when added to the root $\sqrt{ }$ labh- 'take' in an s-stem aorist (past) form,

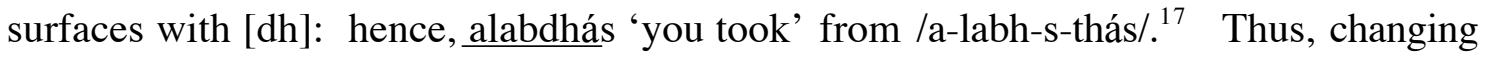
the voicing feature of a voiceless aspirate yields a voiced aspirate, and this suggests that the two types differ only in voicing, not in the nature of their aspiration.

Given all this evidence, it seems best to admit that from the standpoint of their phonological behavior, the voiced aspirates and the voiceless aspirates show a parallel type of aspiration. There is thus little to be gained from the arbitrary splitting that B\&M and $\mathrm{K} \& \mathrm{~L}$ impose on the phenomenon of aspiration in all processes and contexts - for instance into an autosegment for voiced aspiration and something different for voiceless aspiration. In fact, it would seem that a complication must be introduced into the grammar of Sanskrit under such an approach to aspiration, since there would be a need for one rule 
to deaspirate voiceless aspirates in word-final position (as with $\underline{\mathrm{kapr} \geq \mathrm{th}}-$ ) and a different rule to deaspirate voiced aspirates in the same position (as with samidh-).

Moreover, the one piece of evidence that B\&M give for a major (representational) difference between voiced and voiceless aspiration turns out to be nonevidence. This evidence has to do with the differential behavior regarding the aspiration throwback effect evinced by the root $\sqrt{ }$ prach- 'ask' and its final voiceless aspirate, on the one hand, versus a

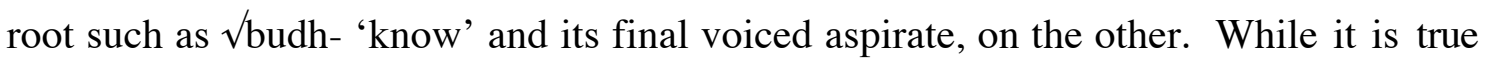
that $\sqrt{ }$ prach- forms a future stem praks $\geq$ ya- and not $*$ phraks $\geq$ ya-, it is not at all clear that the future stem has to be derived from a root form with a voiceless aspirate. That is, while $\sqrt{ }$ prach- does behave in some ways like a full-fledged root, with derivatives such as pr $\geq$ cchá- 'question', there also exist apparently related derivatives that do not have a voiceless aspirate: e.g., prasvna- 'question'. The occurrence of forms such as prasvna-, apparently from a root form $\sqrt{ }$ prasv- is significant, since a future stem praks $\geq$ ya- is exactly what would be expected from the root form $\sqrt{ }$ prasv-. Diachronically, too, it is clear that the -ch- in $\sqrt{ }$ prach- is the result of a special formative that characterizes present stems. ${ }^{18}$ Thus, the future stem associated with $\sqrt{ }$ prach- is actually irrelevant to the question of aspiration throwback and its (non-)relation to the voiceless aspirates. ${ }^{19}$

There are two other forms, however, which are somewhat like praks $\geq$ ya- in not showing aspiration throwback onto a voiceless stop and thus need further comment. For instance, the stem kapr $\geq$ th- 'penis', given above in (11), loses its stem-final aspiration in, e.g., the nominative singular $(\underline{\operatorname{kapr} \geq t})$, but that aspiration does not reappear on either of the other voiceless stops in the word (i.e., we find neither $* \underline{k h a p r} \geq t$ nor $* \underline{k a p h r} \geq t)$ ). Just as in the situation with $\sqrt{ }$ prach-, then, what B\&M treat as 'voiceless aspiration' is at issue here. The other form, however, offers a slightly different problem. The root $\sqrt{ } \mathrm{tr} \geq \mathrm{h}$ - 'crush' forms a future with the suffix -sya-, and the latter expectedly occasions deaspiration of 
the root final voiced aspirate $\underline{h}$, yet there is no accompanying aspiration throwback: the future stem is tarks $\geq$ ya- not $*$ tharks $\geq$ ya-.${ }^{20}$ These forms admittedly do suggest that there is some difference between voiced aspiration and voiceless aspiration, a situation that is consistent with B\&M's treatment. On the other hand, given the morpholexical solution that we favor here - one in which participation in aspiration throwback is not an automatic property of a root having a final voiced aspirate, even when the root-initial stop is voiced (cf. the discussion of gutsa- below) — we simply have to say that, for whatever reason (most likely analogical interference from unaspirated forms of the $\operatorname{root}^{21}$ ), the root $\sqrt{ } \mathrm{tr} \geq \mathrm{h}$ - simply failed to get on the aspiration throwback 'list'. In a sense, the occurrence of such exceptions, even if they might appear to have a phonological basis (e.g., if one claims a systematic basis to the absence of B\&M's so-called 'voiced aspiration' with voiceless stops), is also consistent with the morpholexical approach advocated here. It should be noted that if there were no phonological-behavioral evidence uniting the voiced and voiceless aspirates, then the absence of *tharks $\geq$ ya- and $*$ khapr $\geq \mathrm{t} / \mathrm{kaphr} \geq \mathrm{t}$ would probably favor B\&M's approach. But, $\underline{\mathrm{dh}}$ and th do in fact show parallel behavior - and do so in several ways, as discussed above - and that behavior is a sufficient counter, we submit, to this one possible strike against a nonphonological account.

\subsection{On Bartholomae's Law Forms and -DDh- Clusters}

To continue with details of the $\mathrm{B} \& \mathrm{M} / \mathrm{K} \& \mathrm{~L}$ analysis: we noted above that, in order to account for the failure of aspiration throwback to occur in the participle buddha- and other forms like it which have undergone Bartholomae's Law, B\&M claim that a cluster such as - $\underline{\mathrm{ddh}}$ - is in fact aspirated throughout the cluster, and they hold that 'the written form reflects orthographic convention and not phonetic fact'. A number of related points need to be made here, however. First, the Sanskrit writing system notes many details of phonetic realization, but not necessarily consistently; thus, one could say that the burden of proof is on those who claim that some aspect of the written form is merely an 
orthographic convention - i.e., on B\&M - rather than on one who would take the spelling at face value. Second, there are spellings with doubled aspirated consonants, especially - but not necessarily exclusively - in expressive forms like Vedic akhkhalïkrtya 'shouting with joy; making (the noise) akhkhala', or jajhjhatír 'hissing', ${ }^{22}$ and these show that such spellings were available. The fact that they were not consistently used for Bartholomae's Law clusters as in buddha- then becomes somewhat problematic for B\&M's position, in which - $\underline{\mathrm{ddh}}-$ is viewed as aspirated throughout the cluster. In the interests of fairness, though, it must be admitted that until a thorough examination of Sanskrit spelling practices is available, perhaps the safest thing to say is that the orthographic issue raised by B\&M is moot, and favors neither one position nor the other. At the very least, though, the interpretation of the - ddh- clusters is not obviously simply a matter of spelling convention, as B\&M suggest.

The K\&L approach to the treatment of the -DDh- clusters, on the other hand, runs into a factual problem. While their decision to extend from their original use for accentual matters the notions recessive versus nonrecessive portions of a syllable to matters involving the spread of a feature such as aspiration can be recast in terms of licensing, (cf., e.g., Goldsmith 1990, Kenstowicz 1993: 285-291, and Steriade 1995: 158-165, among many others), the more important issue is the fact that voiced aspirated stops can indeed occur in syllable-final position. ${ }^{23}$ For example, in the word budhna- 'bottom', the syllabification is [budh\$na-], to judge from the description of syllabification prescribed in the prátisvákhyas as summarized by Allen (1953: 82): 'the general rule is that an intervocalic consonant, as also an absolute initial or initial group, belongs with the following vowel, but that the first consonant of a medial group belongs with the preceding vowel'. Hence, budhna- has the voiced aspirate in a recessive (syllable-final) position. ${ }^{24}$ 
In any case, though, ordering (or ranking) of the Bartholomae's Law effect ahead of any final deaspiration process (or constraint) would be sufficient to prevent its apparent reassociation, as indicated in (13):

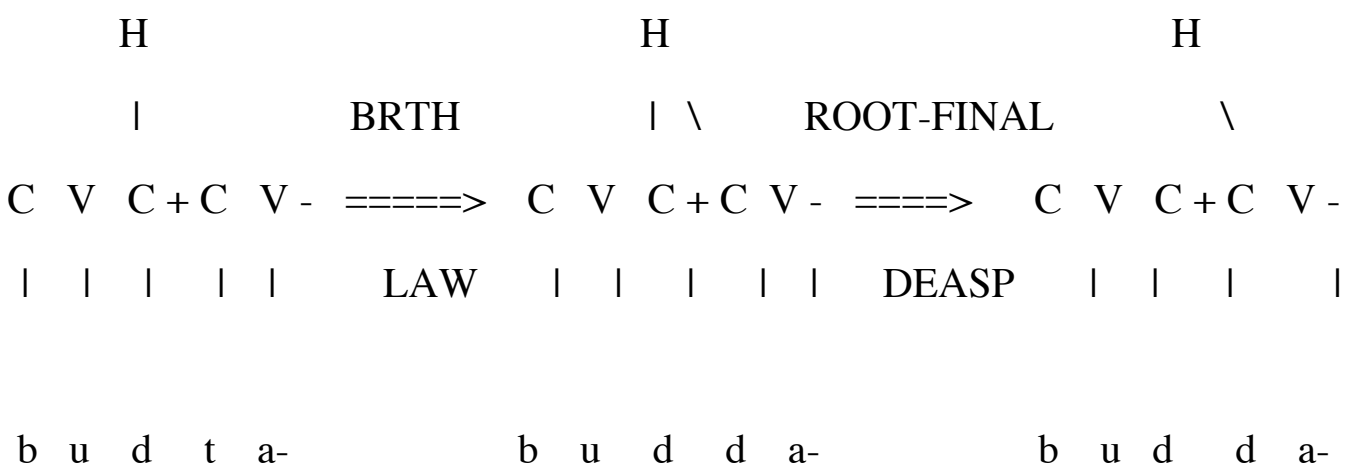

With such an ordering (or ranking), there is no need for the apparent reassociation of $\mathrm{H}$ (or [spread gl(ottis)]) with a root-initial segment, since it is already associated with a segment after the operation of Bartholomae's Law. ${ }^{25}$

\subsection{Devoicing and Revoicing Problems}

The autosegemental analysis depends on its (voiced) aspiration autosegment being 'liberated' (delinked), once its host segment is devoiced and thus being in need of finding a new host with which to associate (relink). It is thus a curious fact about this analysis that the segment from which aspiration is delinked can in fact surface as voiced, if a voiced segment follows it. That is, there exist more than the allomorphs given in (2) and repeated here for convenience of reference:

bVdh- $\sim$ bhVt- $\sim$ bVd-

Namely, there also occurs the allomorph bhud-, which is found in various voicing environments where deaspiration is nonetheless called for - e.g., before a voiced obstruent, as with the instrumental plural suffix - bhis (thus, bhud-bhis) or post-lexically when the nominative singular is followed by a voiced segment (e.g. ...bhud \#\# a...). ${ }^{26}$ What is problematic about this fact for the $\mathrm{B} \& \mathrm{M} / \mathrm{K} \& \mathrm{~L}$ analyses is its implication that the final segment of a relevant root could actually be an appropriate bearer of the voiced 
aspiration (eventually - i.e., later on - in a derivational approach); the absence of aspiration from that position must be stipulated, therefore, and its reappearance on a rootinitial segment is not an automatic consequence of delinking.

\subsection{Dealing with Exceptionality}

A fifth major problem faced by autosegmental analysts of Sanskrit aspiration is that there is no natural way in their framework to account for the exceptional behavior of certain words - for instance, words that, under certain assumptions, can be analyzed as failing to show expected aspiration throwback effects.

These forms include the lexical item gr $\geq$ tsa- 'wise', which is at least diachronically related to the root $\sqrt{ } \mathrm{gr} \geq \mathrm{dh}$ - 'be greedy' and thus might be expected to show aspiration throwback since $\sqrt{ } \mathrm{gr} \geq \mathrm{dh}$ - is historically a diaspirate. In this case, though, it turns out that $\sqrt{ } \mathrm{gr} \geq \mathrm{dh}$ - happens not to occur in any of the relevant forms - except for $\mathrm{gr} \geq \mathrm{tsa}-\mathrm{-}$ that could show aspiration throwback and so this root may very well have been relexicalized as being only finally aspirated. Moreover, the synchronic derivation of $\mathrm{gr} \geq \mathrm{tsa}-$ 'wise' from $\sqrt{ } \mathrm{gr} \geq \mathrm{dh}$ - 'be greedy' is not a transparent one. There are other forms which are like gr $\geq$ tsa-, in being potentially irrelevant perhaps equally irrelevant for the matter at hand, but which are still worth noting. These include grap-sa- 'tuft, bunch' which is historically connected with the root $\sqrt{\text { gr }} \geq$ bh- 'take, seize' (see Mayrhofer 1956 et seqq.: s.vv.); if the connection was strong enough (i.e., sufficiently motivated from a semantic standpoint) to be available to speakers synchronically at any point throughout the history of Sanskrit, then grap-sa-, with no aspiration throwback even though presumably from /grbh-sa-/, would be another form demonstrating the non-phonologicality of this process. The same can be said of drap-sa- 'drop', from a Proto-Indo-European root *dhrebh-, as long as at least some speakers linked this word with the root $\sqrt{ } \mathrm{dr} \geq \mathrm{bh}$ - 'string together' - a connection which, though not necessarily compelling, is certainly permitted by the semantics of the forms involved (and possibly reinforced by the rhyme with the 
semantically parallel grap-sa-) but which could only be folk-etymological in nature, given what is known about the Indo-European sources of this noun and the historically unrelated verbal root (see Mayrhofer 1956 et seqq.: s.vv). For each such form, their relevance to assessing the phonological nature of aspiration throwback depends on the strength of what are most likely to be at best rather tenuous synchronic derivations.

A second problematic type of form is like gr $\geq$ tsa-/grapsa-/drapsa- except that the synchronic derivation is quite solidly indicated. In particular, there is gut-sa- 'bunch'27 - undoubtedly a hyper-Sanskritization of guccha- 'bunch, bundle' - which was treated as if Prákrit (it may well be a Dravidian loanword) and 'Sanskritized' by inverse 'overapplication' of the regular correspondence of Sanskrit -ts- to Prákrit -chch-, which is seen, e.g., in the linkage of Sanskrit. matsara- (cf. $\sqrt{ }$ mad- 'be glad; intoxicate') with Prákrit. macchara- 'cheerful; intoxicating' (see Mayrhofer 1956 et seqq.: s.v. and Lee 1986). Interestingly, some native grammarians (opining admittedly rather late in the Sanskrit tradition, in the Unadi-Sutra) folk-etymologically connected gut-sa- with a root لgudh- 'tie' that was 'created' (i.e., posited) by the grammarians in order to explain this and other forms: e.g., gudhera- 'protecting', itself a hyper-Sanskritization of guhera'protector' from the root $\sqrt{\text { guh- }}$ 'hide, cover'. This native analysis of gut-sa- as derived from $\sqrt{ }$ gudh- was proposed even though the supposedly derived noun does not show aspiration throwback. This has a direct bearing on the phonologicality of aspiration throwback, since if it were phonological, and triggered solely by the deaspiration of a voiced aspirated stop before -s-, then deriving the noun from /gudh-sa-/ would be expected to trigger throwback, thus leading to *ghutsa-. The fact that the absence of aspiration throwback in gut-sa- did not prevent the relevant grammarians from making a connection with $\sqrt{ }$ gudh- indicates that - at that time, at least - aspiration throwback was not part of the (automatic) phonology of Sanskrit. Moreover, within the morpholexical approach that we are advocating here, one would simply have to say that $\sqrt{\text { gudh- was not }}$ 
on the list of aspiration throwback triggers; on this approach, complete consistency based on phonological form is not expected.

Third, there are Vedic variants such as $\underline{\operatorname{duks} \geq a}-\underline{\operatorname{dhuks} \geq a}-$ - aorist stems from $\sqrt{ }$ duh- 'milk' - where aspiration throwback reveals itself to be optional. Whatever the diachronic explanation for such variation might be, ${ }^{28}$ it is clear that a purely phonological solution to aspiration throwback - one in which the throwback effect is automatic, given certain conditions, as the autosegmentalists would claim - cannot easily incorporate either the optionality of the processes involved or their lexical restrictedness.

Fourth, phonologically similar, and in one case even identical, suffixes show differential behavior with regard to aspiration throwback, a situation which cannot be accommodated easily into a purely phonological account. For instance, the 2SG active imperative ending —dhi does not trigger aspiration throwback (cf., e.g., dug-dhi '(you) milk!' from $\sqrt{\text { duh-) }}$ whereas the 2PL middle imperative ending -dhvam does (cf., e.g., dhug-dhvam '(you all) milk (for yourselves)!', also from $\sqrt{ }$ duh-). It is hard to see how the difference between $/ \mathrm{dh} /$ and $/ \mathrm{dhv} /$ could be associated with the absence or presence of a triggering of aspiration throwback, yet such would presumably have to be the case in a purely phonological account. Even more telling is the pair Schindler (1976: 634) notes: namely a derived abstract noun in -tva-, where aspiration throwback occurs with the root $\sqrt{ }$ duh-, i.e., pratidhuktva- 'the property of being called fresh milk (prati-duh-)', versus the gerund form with the suffix -tvá- where Bartholomae's Law operates and there is no aspiration throwback, i.e,,_(prati-)dug-dhvá 'having milked'. The exceptionality here comes from similar or identical phonological material behaving differently in terms of triggering (or not) aspiration throwback; from a wider perspective, differential behavior for phonetically identical forms shows that the phenomenon in question cannot be purely phonological. The only way to distinguish the -tw- which triggers aspiration throwback from the -tw- which undergoes Bartholomae's Law and thus occasions no aspiration 
throwback is in terms of precisely which suffix they belong to - i.e., a morphological and lexical (morpholexical) fact, and so clearly a non-phonological property.

A fifth and final problem involving exceptionality is posed by the weak present stem

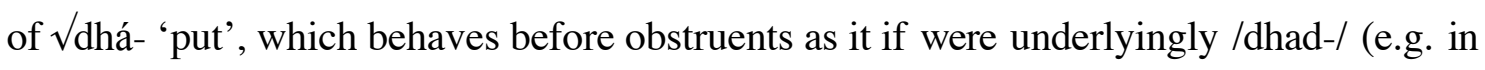
the 3SG middle form dhat-te) rather than the expected /dadh-/ (which is found before vowels and resonants); that is, one would expect a $3 \mathrm{SG}$ middle present $* *$ daddhe (as if from /dadh-te/), so that this root constitutes an exception to Bartholomae's Law and thus seemingly shows aspiration throwback unexpectedly (along with devoicing/deaspiration of the stem final $\underline{\mathrm{dh}}) .^{29}$ Presumably, the variant stem-form her, most likely the result of a restructuring of the stem due to analogy, would have to be listed as a separate allomorph in the lexicon. Admittedly, though, this root is exceptional in anyone's treatment (see Schindler 1976 for discussion of these forms).

\subsection{The General Problem}

More generally, though, it seems that the basic problem with the $B \& M / K \& L$ approach is that it takes a lexically restricted number of processes involving aspiration (recall the exceptional forms discussed above) - ones which are subject to various morphological conditions (such as the near-total absence of aspiration from reduplication) - and tries to turn everything into a matter of pure phonology. We suggest that the first step towards a solution to the aspiration throwback problem (and related effects) must be to recognize the inherently morphological character of these phenomena. Once we begin to incorporate exceptional morpholexical elements into our solution, there is less and less to be gained from a purely phonological solution. Accordingly, we propose, as did Pán $\geq$ ini and others (e.g., Sag and Schindler) before us, that the key to understanding these aspiration phenomena lies in treating them as morphological in character, even if they manipulate some elements of sound structure. 


\section{Towards an Account within a Process Morphology Model}

Such a morphological solution to a deceptively phonological-looking problem is easily accommodated within a Process Morphology approach. ${ }^{30}$ In this morphological framework, a distinction is made between, on the one hand, the set of operations that are employed for morphological marking and, on the other hand, the actual morphological rules which are built up from combinations of these processes employed for the purpose of marking particular categories. All of these, however, count as part of the morphology of the language. For example, in German, umlaut occurs not only alone but also quite (in fact most) frequently in tandem with one or more of various affixes. It is thus an operation that, along with various affixations, is used for the morphological marking of such categories as diminutives and plurals: e.g., some plurals are marked only by umlaut, some by umlaut and suffixation, and some (actually, many) only by suffixation.

Applying this view to Sanskrit, we can say, for example, that voicing assimilation is just one among the several operations that occur in the marking of past passive participles by - among other things - the suffix /-ta-/. There can of course be some phonological conditions on the realization of this operation - e.g., regressive assimilation as the default case but progressive assimilation if the root-final consonant is a voiced aspirate - but, within this framework, such conditions do not automatically make a generalization count as a phonological rule (or constraint) per se. Similarly, palatalization and deaspiration are among the operations that can accompany the marking of a category such as [PERFECT] via reduplication.

As for where and when aspiration throwback occurs in Sanskrit, it is important to recognize, as should be clear from the discussion up to this point, that not only is the number of roots that participate in this phenomenon rather limited (a total of 13 in all), but the full range of Sanskrit morphological categories showing aspiration throwback is itself 
somewhat limited, too, though these categories are far from being a totally disparate set. For verbs, the relevant categories cluster around certain morphosyntactic features mainly involving tense/aspect (future, aorist, and desiderative) and person/number (especially second person, though once also third, and frequently plural number, though also singular). For nouns, the prinicpal morphological concentration of aspiration throwback is to be found in the oblique cases (instrumentals, datives, ablatives, and locative, though also an isolated nominative, accusative, and/or vocative) and in the non-singular numbers (dual and plural, though occasionally also the singular). An enumeration of these categories is given in (14) for verbs and in (15) for nouns:

(14) Verbal Aspiration Throwback Categories

a. verbs marked for one type of FUT stem: that with the suffix -/sya/-, (but not in futures with the suffix -/is $\geq \mathrm{ya} /-$ )

b. verbs marked for one type of DESID stem: that with the suffix -/sa/-, (but not in futures with the suffix $-/$ is $\geq a /-)$

c. verbs marked for either of two types of AOR stems:

i. that formed by any of the -/s/-initial suffixes -/s/- or -/sa/- or -/sis/- (but not by the suffix -/is/-)

ii. that formed without any aorist-suffix at all — but only in such 'root' aorists' second- and third-person singular, where these person/number combinations are marked by the respective underlying suffixes -/s/ and -/t/

d. various 2SG and PL forms, plus one 3SG form:

i. 'primary' 2SG.ACT -/si/ (as for the PRES.IND), plus 'secondary' 2SG.ACT -/s/ (e.g., for the root aorists mentioned in c.ii), 'primary' 2SG.MID -/se/, and imperative 2SG.MID -/sva/

ii. middle $2 \mathrm{PL}-/ \mathrm{dhve} /$ and -/dhvam/ 
iii. 'secondary' 3SG.ACT -/t/ (as for the root aorist above)

(15) Nominal Aspiration Throwback Categories: (mainly) case-forms of root nouns (but cf. (d) for a derivational category)

a. M/F.NOM.SG. (-/s/ > $\varnothing-$ though possibly just $-\varnothing)$, plus NTR.NOM/ACC.SG. $(-\varnothing)$ and M/F/NTR.VOC.SG. (-Ø)

b. the '-/bh/...'-cases: e.g., the INST.PL (-/bhis/), plus the DAT/ABL.PL (-/bhyas/) and the INST/DAT/ABL.DU (-/bhyám/), all of which trigger external (post-lexical) sandhi

c. LOC.PL (-/su/), also an external-sandhi trigger

d. -/tva/- abstract noun forming suffix.

With regard to aspiration throwback outside of bare-root contexts, we thus prefer to analyze it as one of the operations which accompanies certain types of affixation namely,those processes which add the affixes noted in (14) and (15) above to a particular set of roots: in particular, those lexically marked ('on the list', so to speak) as being able to undergo the throwback. The realizational rules for such categories might take the form exemplified in (16) for the vocative singular of nouns and in (17) for the 2PL.MIDDLE.PRESENT of verbs (the latter additionally marked with the suffix -dhve), where the first line represents the relevant morphosyntactic features, the second line (in slashes) shows the schematic phonological shape of the root, and the fourth line indicates the changes effected in that phonological string in such a way as to help generate the surface allomorph which realizes the relevant set of features (although both further morphological rules and automatic phonological processes may later apply before the required surface form is obtained): 
(16)

$[+\mathrm{NOUN},+\mathrm{VOC} .,+$ SG.]

$/[\mathrm{C}$, -continuant, +voiced $][+ \text { segment }]_{1}[\mathrm{C},+$ +voiced, +aspirated $\left.]\right) /$

$\begin{array}{lllll}1 & 2 & 3 & ->\end{array}$

$/[1,+$ aspirated $] 23 /$

(17) [+VERB, +2, +PL, +PRES, +IND, +MID]

$/([\mathrm{C},<-$ continuant, + voiced $>])[+ \text { segment }]_{1}([\mathrm{C},<+$ voiced, + aspirated $>]) /$

$\begin{array}{lllll}1 & 2 & 3 & ->\end{array}$

$/[1,<+$ aspirated $>] 23+\underline{\text { dhve/ }}$

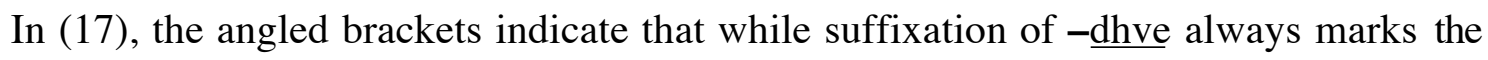
relevant morphosyntactic feature combination, aspiration throwback depends on certain conditions being met. The parentheses in the same rule allow for both vowel-initial and vowel-final root shapes (where throwback is obviously impossible but -dhve is still suffixed.

Moreover, we would posit what can be called 'meta-redundancy-rules', or 'metatemplates' (cf. Janda \& Joseph 1991, 1999) which serve to parse the various realizational rules and express generalizations across them - thereby expressing the unity of, for example, all the instances of suffix-initial -/s/ shared by the verbal $2 \mathrm{SG}$ rules respectively for ACT primary -/si/, secondary -/s/, MID primary -/se/, and IMPER -/sva/ (perhaps also relatable to the further verbal rules for FUT -/sya/-, DESID -/sa/-, and AOR -/s/, -/sa/-, or -/sis/-, as well as the toot-nominal rules for M/F.NOM.SG -/s/ and LOC.PL -/su/. ${ }^{31}$ Similar redundancy-stating metarules and the 'constellations' they express (see footnote 31) likewise allow groupings across the various aspiration-throwback-containing processes for $-/ \mathrm{bh} / \ldots$-.. suffixation, -/dhv/...- suffixation, and the remaining, suffixless aspiration throwback forms. Finally, we would combine (i) lexical listing for idiosyncratic 
forms with (ii) lexical-correspondence (redundancy) rules (cf. Janda 1987, and references there, on the available variety of such devices) in order to handle exceptional morpheme combinations such as those seen in the various allomorphs of $\sqrt{ }$ dhá- which fail to trigger Bartholomae's Law but do show aspiration throwback: e.g., $/$ dhad+te/[3.SG.PRES.IND.MID.] $=$ [dhatte] $($ whereby /dhá/ and /dhad $/$ - plus $/ \mathrm{dadh} /$ alternate).

On the subject of lexical listing, we raise here the possibility that aspiration throwback in Sanskrit may have been totally lexicalized and hence that it would only have been a redundancy-expressing correspondence statement. On this approach, Sanskrit speakers would simply have memorized for each of the 13 aspiration throwback roots those particular forms, both nominal and verbal, which show the throwback effect. The number of relevant forms would not have been huge and so would not have been a large burden on a speaker's memory. We are emboldened to raise this possibility because a similarly morpholexicalized process in another language has recently been analyzed as completely lexicalized, and the dephonologized operation in question shows up in even far more forms than does aspiration throwback in Sanskrit. At issue here is umlaut in Modern High German, which Féry 1996 and some others have treated as essentially only a lexical phenomenon. For them, the vowel fronting which constitutes Modern High German umlaut is preferably to be analyzed via massive lexical listings which pair an umlauted stem together with one or more affixes (or with a meaning other than that of a bare stem). Here, the only rules involved are redundancy statements which parse such complex listed forms and relate their parts to those of other complex words (and to the component morphemes and/or formative processes mentioned in the redundancy rules themselves). The evidence for this approach in Modern High German is rather strong: even in cases where umlaut is regular (exceptionless), it is rarely productive. In short, umlaut in Modern High German seems to be dying - though it is doing so via 
petrification, and thus through lexicalization is leaving behind widespread traces of its former lively presence. But it is dying at different rates in different categories and this provides a somewhat morbid but very real confirmation of its morpholexical nature.

Janda 1998a discusses this completely lexicalized approach to umlaut but concludes that, in the event that an analysis of umlaut other than one with lexical listings should be preferable, then one making use of the alignment constraints of Optimality Theory is surely preferable to any of various nonlinear, née autosegmental, approaches still maintained by some. Thus, e.g., Janda 1998b exploits the fact that there is no longer any need for floating autosegments in an analysis of Modern High German umlaut that makes use of OT's constraints on, e.g., alignment and faithfulness, which allow abandonment of derivations and their associated intermediate steps. The tableaux for such a morpholexical OT account of umlaut can consist simply of a set of ALIGN constraints which require the alignment of (the left edge of) a particular suffix with (the right edge of) a root whose last vowel is [+front] (alternatively, [-back]). These constraints are ranked higher than FAITHFULNESS for umlaut-triggering suffixes but lower than the latter constraint for nonumlaut-triggering suffixes. Here, still, the morpholexical nature of Modern High German vowel-fronting remains unmistakable.

The option of adopting such an analysis for Sanskrit aspiration throwback is readily available. For the Sanskrit case, we would likewise require a set of ALIGN constraints, but here the relevant generalizations require the alignment of (the left edge of) a particular suffix with (the right edge of) a root whose first consonant is [+voice, +aspirated]. These constraints are ranked higher than FAITHFULNESS for aspiration-throwback-triggering suffixes but lower than the latter constraint for non-aspiration-throwback-triggering suffixes. One example each of such constraint rankings is given below in (18); we note that, for ease of exposition, these tableaux have been considerably simplified: relevant constraints other than those just mentioned have been omitted and we therefore have 
likewise factored out the deaspiration which occurs in all aspiration-throwback contexts. Nevertheless, we believe that the flavor of an alignment-based OT account of Sanskrit aspiration throwback comes through from these tableaux.

(18) Sanskrit Aspiration Throwback Tableaux

\begin{tabular}{|c|c|c|}
\hline $\begin{array}{l}\text { dugh+dhve/'You all } \\
\text { milked' } \\
(\approx \text { 'milk' + '2.pl.mid.') }\end{array}$ & $\begin{array}{l}\text { ALIGN (1st-C=voiced-asp. root, right, } \\
\text { [ATB-triggering] suffix - } d h v e, \text { left })\end{array}$ & "FAITHFULNESS \\
\hline$\overline{\text { [dug+dhve] }}$ & "*! & \\
\hline [dhug+dhve] & & $*$ \\
\hline
\end{tabular}

\begin{tabular}{||c||l|l||}
\hline $\begin{array}{c}\text { /dugh+dhi/ 'Milk! [2.sg.act.] } \\
(\approx \text { 'milk' + '2.sg.imper.act' })\end{array}$ & FAITHFULNESS & $\begin{array}{r}\text { ALIGN (1st-C=voiced-asp. root, right, } \\
\text { [ATB-triggering] suffix }- \text { dhi, left })\end{array}$ \\
\hline \hline [dug+dhi] & & $*$ \\
\hline [dhug+dhi] & $* !$ & \\
\hline
\end{tabular}

Given that OT allows, for the same phenomenon, both in essence purely morpholexical treatments like that just sketched, and purely phonological accounts relying entirely on syllable structure and its consequences for phonological configurations, it is clear that OT in no way resolves the seemingly eternal battle between phonologists and morphologists over the best analysis of alternations like Sanskrit aspiration throwback. Our own view is that OT (especially because it contains the function GEN, which generates essentially all possible analyses and related configurations of sound) is rather like Pandora's Box; it strikes us as including literally the full gamut of possible analyses, ranging from the very best to the very worst. Nevertheless, since OT, to repeat, offers no rewards for floating autosegments or intermediate derivational steps (even via universal association conventions), we welcome the opportunity it has given morphologists to reclaim Sanskrit aspiration alternations and other morphological property, so to speak, that once seemed permanently expropriated by phonologists. Both an OT morphological 
account and a Process Morphological account (as sketched above) agree in their overall orientation and in their major aspects. On the other hand, in saying, we do not thereby wish to downplay the fundamental insight of Process Morphology, which, true to its name, reconceptualizes all non-root 'morphemes' as processes - or rules - rather than as 'things' (only roots and built-up stems are 'things'). While the present paper cannot pursue this idea to any appreciable length, the OT revolution's effect of leading scholars to rework rule-based analyses in terms of constraint-based ones (with constraints which are often not identical but sometimes quite similar to earlier analysts' rules) raises the intriguing possibility that an OT-oriented recasting of Process Morphology could conceptualize every (non-root) 'morpheme' as a constraint. ${ }^{32}$

Most importantly, though, we would emphasize the following: the mere fact that morphological operations manipulate sounds does not make them phonological in nature. After all, morphology like that above must be realized through sounds, and so, ipso facto, even highly lexically specific operations - such as Aspiration Throwback - are best treated as basically morphological in nature although they affect sounds. In short, then, we retain the well-supported basic insight of Sag and Schindler — and Pánini before them - that the Sanskrit aspiration throwback effects are basically a matter of morphology, and so we conclude that the attempts of autosegmentalists to deal with this purely in phonological terms are poorly motivated. ${ }^{33}$ While B\&M and especially K\&L have shown how autosegmental phonology would describe the facts in question (and have thereby hinted at the sorts of alternative analyses that its various successor theories might be tempted to propose), they have not shown that there is anything to be gained from such an account. Indeed, as we have demonstrated at length here, their attempts simply cannot get around the fact that, in their analyses, problems abound. 


\section{References}

Allen, W. S. 1953. Phonetics in Ancient India. London: Oxford University Press.

Anderson, S. 1982. Where's Morphology?, Linguistic Inquiry 13.4.571-612.

Anderson, S. 1992. A-morphous Morphology. Cambridge: Cambridge University Press.

Bare, J. 1980. Phonetics and Phonology in Pánini. The System of Features Implicit in the

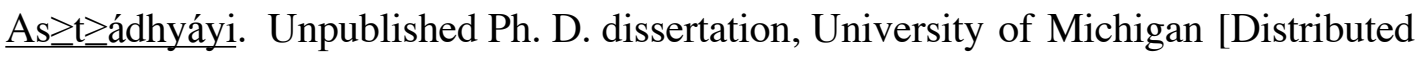
by University Microfilms International, \#75-29,175].

Beard, R. 1995. Lexeme-morpheme base morphology : a general theory of inflection and word formation. Albany : State University of New York Press.

Benguerel, A. \& T. Bhatia. 1980. Hindi Stop Consonants: an Acoustic and Fiberscopic Study, Phonetica 37. 134-148.

Blevins, J. 1995. The syllable in phonological theory. In Goldsmith 1995, pp. 206-244.

Borowsky, T. and A. Mester. 1983. Aspiration to Roots. Remarks on the Sanskrit Diaspirates, in Papers from the Nineteenth Regional Meeting of the Chicago Linguistic Society, pp. 52-63.

Broe, M. 1991. Paradox Lost: A Non-derivational Approach to Grassmann's Law. In: S. Bird (ed.) Declarative Perspectives on Phonology (Edinburgh Working Papers in Cognitive Science, Vol. 7). Edinburgh: Centre for Cognitive Science, University of Edinburgh, pp. 1-19.

Clements, G. N. 1985. The geometry of phonological features. Phonology 2.225-252.

Clements, G.N. \& E. Hume. 1995. The internal organization of speech sounds. In Goldsmith 1995, pp. 245-306.

Collinge, N. 1985. The Laws of Indo-European. Amsterdam: John Benjamins Publishing Co. 
Davis, K. 1987. Phonetic Cues to the Hindi Voiced Aspirates, paper presented at the 9th South Asian Language Analysis Roundtable (SALA 9) at Cornell University, June 5, 1987.

Dixit, P. 1979. Aspiration: what is it and how is it produced?, Journal of the Acoustical Society of America 65: suppl. 1, p. 23.

Dixit, P. 1987. In defense of the phonetic adequacy of the traditional term 'voiced aspirated'. Proceedings of the Xith International Congress of Phonetic Sciences (Tallinn), Vol. 1.145-148.

Ejerhed, Eva. 1981. The analysis of aspiration in Sanskrit phonology. Nordic Journal of Linguistics 4.2.139-159.

Féry, C. 1996. The trochaic ideal. Unpublished ms., University of Tübingen.

Gamkrelidze, T. \& V. Ivanov. 1972. Lingvisticeskaja tipologija i rekonstrukcija sistemy indoevropejskix smycnyx. In: S. Bernstejn et al. (eds.), Conference on comparativehistorical grammar of the Indo-European languages. Moscow: AN SSSR, pp. 15-18.

Goldsmith, J. 1990. Autosegmental and Metrical Phonology. Oxford: Blackwell.

Goldsmith, J., ed. 1995. Handbook of Phonological Theory. Oxford: Blackwell.

Golston, C. 1996. Direct optimality theory: Representation as Pure Markedness. Language 72.713-748.

Hoard, J. 1975. On Incorporating Grassmann's Law into Sanskrit Phonology, in Cogen et al., eds., Proceedings of the First Annual Meeting of the Berkeley Linguistics Society. Berkeley: Department of Linguistics, University of California, pp. 207-220.

Janda, R. 1983. 'Morphemes' Aren't Something that Grows on Trees: Morphology as More the Phonology than the Syntax of Words, in Richardson et al., eds., Papers from the Parasession on the Interplay of Phonology, Morphology, and Syntax. Chicago: Chicago Linguistic Society, pp. 79-95. 
Janda, R. 1987. On the Motivation for an Evolutionary Typology of Sound-Structural Rules. Unpublished Ph.D. dissertation, UCLA. [University Microfilms International No. 8720023.]

Janda, R. 1998a. German Umlaut: Morpholexical All the Way Down from OHG to NHG (Two Stützpunkte for Romance Metaphony). Rivista di Linguistica 10(1), 165-234.

Janda, R. 1998b. More than 2 Points on Umlaut in Modern Standard High German.. Paper presented at Annual Meeting of the Linguistic Society of America (New York), January 1998.

Janda, R. \& B. Joseph 1986. One Rule or Many? Sanskrit Reduplication as Fragmented Affixation. In Studies on Language Change, ed. B. Joseph (Ohio State University Working Papers in Linguistics Vol. 34), pp. 84-107 [earlier version in ESCOL '85. Papers from the Second Eastern States Conference on Linguistics. 1986, pp. 103119].

Janda, R. \& B. Joseph. 1991. Meta-Templates and the Underlying (Dis-)Unity of Reduplication in Sanskrit. In: ESCOL '91. Proceedings of the Eighth Eastern States Conference on Linguistics. Columbus: The Ohio State University Department of Linguistics, pp. 160-173.

Janda, R. \& Joseph, B. 1999. . The Modern Greek Negator mh(n)(-) as a Morphological Constellation. In: G. Babiniotis (ed.), Greek Linguistics: Proceedings of the 3rd International Conference on Greek Linguistics. Athens: Elinika Gramata, pp. 341351.

Joseph, B. \& Janda, R. 1988a. On the Unity of Sanskrit Aspiration. Discussion Papers for the Sixth International Phonology Meeting and Third International Morphology Meeting, Volume 1: Phonology (Wiener Linguistische Gazette, Supplement 6), pp. 29-31. 
Joseph, B. \& Janda, R. 1988b. The How and Why of Diachronic Morphologization and Demorphologization. In: M. Hammond \& M. Noonan (eds.), Theoretical Morphology: Approaches in Modern Linguistics. Academic Press, San Diego, CA, pp. 193-210.

Joseph, B. \& R. Wallace. 1994. Proto-Indo-European Voiced Aspirates in Italic: A Test for the Glottalic Theory. Historische Sprachforschung 107.244-261.

Kaye, J. \& J. Lowenstamm. 1985. A Non-linear treatment of Grassmann's Law. In S. Berman et al., Proceedings of NELS 15. 1985. Amherst: GLSA, pp. 220-233.

Kenstowicz, M. 1993. Phonology in Generative Grammar. Oxford: Blackwell.

Kiparsky, P. 1965. Phonological Change. Unpublished MIT Ph.D. Dissertation.

Kiparsky, P. 1995. The phonological basis of sound change. In Goldsmith 1995, pp. 640670.

Ladefoged, P. 1975/1982/1993. A Course in Phonetics $\left(1^{\text {st }} / 2^{\text {nd }} / 3^{\text {rd }}\right.$ editions $)$. New York: Harcourt Brace..

Ladefoged, P. 1976. The Stops of Owerri Igbo, Studies in African Linguistics, suppl. 6, pp. 147-163.

Lee, G. 1986. Diglossia in Ancient India. In: Studies on Language Change. Ohio State University Working Papers in Linguistics 34 (1986), pp. 151-164.

Matthews, P. 1972. Inflectional Morphology: A Theoretical Study based on Aspects of Latin Verb Conjugation. Cambridge: Cambridge University Press.

Marantz, A. 1982. Re Reduplication. Linguistic Inquiry 13.435-482.

Mayrhofer, M. 1956 et seqq. Kurzgefasstes etymologisches Wörterbuch des Altindischen. Heidelberg: Carl Winter.

McCarthy, J. 1979. Formal Problems in Semitic phonology and morphology. MIT Doctoral dissertation [published, 1985, by Garland Press, NY]. 
McCarthy, J. 1981. A prosodic theory of noncatenative morphology. Linguistic Inquiry $12.373-418$.

McCarthy, J. \& A. Prince 1986. Prosodic morphology. Unpublished ms., University of Massachusetts/Brandeis University.

McCarthy, J. \& A. Prince. . 1995. Prosodic morphology. In Goldsmith 1995, pp. 318366.

Ohala, J. . 1995. Experimental phonology. In Goldsmith 1995, pp. 713-722.

Phelps, E. 1975. Sanskrit Diaspirates, Linguistic Inquiry 6.447-464.

Prince, A. \& P. Smolensky. 1993. Optimality theory: Constraint interaction in gneerative grammar. Unpublished ms., Rutgers University/University of Colorado, Boulder.

Sag, I. 1974. The Grassmann's Law Ordering Pseudo-Paradox, Linguistic Inquiry 5.591607.

Sag, I. 1976. Pseudosolutions to the Pseudoparadox: Sanskrit Diaspirates Revisited, Linguistic Inquiry 7.609-622.

Schiefer, L. 1987. Perceptual and Acoustic Correlates of Hindi Breathy Voiced Stops. Paper presented at the 9th South Asian Language Analysis Roundtable (SALA 9) at Cornell University, June 5, 1987.

Schiefer, L. 1988. 'Voiced aspirated' or 'breathy voiced' and the case for articulatory phonology. Paper presented at the Sixth International Phonology, Krems (Austria), July 1988 .

Schindler, J. 1976. Diachronic and Synchronic Remarks on Bartholomae's and Grassmann's Law, Linguistic Inquiry 7.622-637.

Singh, R. \& R. Agnihotri. 1997. Hindi Morphology: A Word-Based Description. Delhi: Motilal Banarsidass.

Stemberger, J. 1980. Another Look at Grassmann's Law, Glossa 14.113-135. 
Stump, G. 2001. Inflectional morphology : a theory of paradigm. Cambridge: Cambridge University Press, 2001

Steriade, D. . 1995. Underspecification and markedness. In Goldsmith 1995, pp. 114-174.

Vaux, B. 1992. Gemination and Syllabic Integrity in Sanskrit. Journal of Indo-European Studies 20.3-4.283-303.

Whitney, W. 1889. Sanskrit Grammar. Cambridge: Harvard University Press. (2 ${ }^{\text {nd }}$ ed.).

Yadav, R. 1984. Voicing and aspiration in Maithili: A fiberoptic and acoustic study. Indian Linguistics 45.1-4.1-30.

Zwicky, A. 1965. Topics in Sanskrit Phonology. Unpublished MIT Ph.D. Dissertation. 


\footnotetext{
* An earlier version of this paper was presented at the 9th South Asian Language Analysis Roundtable (SALA 9) at Cornell University, June 5, 1987. We are especially grateful to Hans Hock and David Odden, for helpful suggestions and comments regarding this paper, and to Raj Singh, for encouraging us to reopen our consideration of this still quite timely topic.
}

${ }^{1}$ Such a practice is of course entirely defensible for pedagogical purposes, which after all is the guiding principle behind a textbook; too much detail in the presentation of examples requires additional explanation that can distract the student from the point being made.

2 'Grassmann's Law' is the name given to the sound change(s) by which the first of two Proto-Indo-European (PIE) aspirated stops in successive syllables became deaspirated: i.e., schematically, $C^{\mathrm{h}} \ldots \mathrm{C}^{\mathrm{h}} \rightarrow \mathrm{C} \ldots \mathrm{C}^{\mathrm{h}}$. The results of this change are found in both Greek and Indic (and possibly also in Tocharian), and it seems to have taken place independently in each of these branches. The label 'Grassmann's Law' is also often applied to the synchronic rule(s) found in these branches as the aftermath of the earlier sound changes. See Collinge 1985 for general discussion and for references both to the considerable early literature and to more recent works on this phenomenon.

${ }^{3}$ Vaux 1992 discusses Bartholomae's Law to some extent, but he does so in the context of his main focus, namely gemination in Sanskrit.

${ }^{4}$ For each of these, monoaspirate alternant forms are found, i.e., $\sqrt{ }$ drákh-, $\sqrt{ }$ drágh-, and $\sqrt{ }$ bharb- all occur.

${ }^{5}$ Steriade's statement contains a potential pitfall for the uninitiated with regard to IndoEuropean, in that she here seems to be assuming the often-criticized 'Glottalic Theory' of Gamkrelidze \& Ivanov 1972 (see Collinge 1985 for additional references), for whom Grassmann's Law is to be treated as a rule of allophonic distribution in PIE rather than a 
sound change that took place on the way from PIE to Greek and to Indic respectively. See Joseph \& Wallace 1994 for a critique of this view.

${ }^{6}$ We are assuming that by 'stem' here she essentially means 'root'.

7 Contrast Marantz (1982)'s mention of the Sanskrit reduplication rule with the enumeration in Janda \& Joseph 1986 of some 10 or more distinct reduplication templates and hence rules.

${ }^{8}$ In a feature-geometric analysis, the association of devoicing and deaspiration follows automatically from the fact that [spread (gl[ottis])] and [voice] (also known as [+slack vocal cords]) are sisters both dominated by a glottal (or laryngeal) node whose deletion removes both of them simultaneously.

${ }^{9}$ It is important to point out that $\sqrt{ }$ prach- is essentially the only root for which a claim concerning aspiration throwback onto a voiceless stop could be tested, since all other roots of the shape T/DVTh- (where $\mathrm{T}=$ voiceless stop and $\mathrm{D}=$ voiced stop) are so-called $\underline{\text { set }} \geq$ roots. As a result, they show insertion of the vowel -i- in root-final position before most suffixes; thus, with set $\geq$ roots, there is never final devoicing/deaspiration to trigger aspiration throwback.

${ }^{10}$ Even if the aspiration of the root-final ch were somehow represented autosegmentally, the liberated autosegment could not reassociate onto the root-initial $\mathrm{p}$, since $\mathrm{p}-$ being a voiceless stop - is not a possible bearer of the aspiration autosegment.

${ }^{11}$ See, however, Janda \& Joseph 1986 for further discussion and especially for some details regarding reduplicative formations that do show aspiration in the reduplicative prefix. 12 As discussed by Kenstowicz (1993: 631-633), McCarthy \& Prince 1986 replace templatic prespecification with melodic overwriting (due to cases like English cancer-

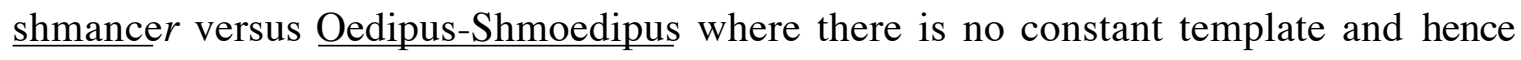
apparently nothing to prespecify). 
${ }^{13}$ See also the discussion in Joseph \& Janda 1988b. Some of these arguments are anticipated in Ejerhed 1981, though stated in somewhat different terms, and in any case, we disagree with her conclusion that the aspirated stops of Sanskrit are to be treated as clusters of plain stops plus /h/ (as Zwicky 1965 did for the voiceless aspirates). In particular, the cluster analysis, as Ejerhed herself realizes, complicates the statement of certain cluster simplification rules and runs counter to the behavior of the aspirates in Sanskrit poetic metres. Furthermore, while she counts the reduplicative behavior of aspirates as favoring a cluster analysis - recall, as above, that there is generally no aspiration in reduplication we note that there are some exceptional cases in which aspiration occurs in reduplication

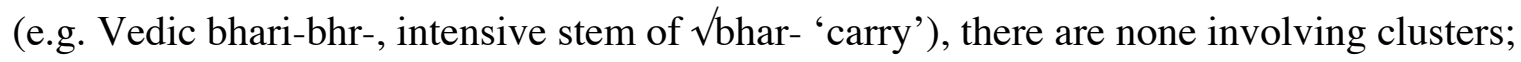
similarly, while she treats word-final deaspiration as just a case of final cluster reduction, there again are exceptions with nonaspirates (e.g. Vedic (VS) úrk, NOM.SG of úrj'nourishment') but none with aspirates.

${ }^{14}$ There is a rather substantial literature on the phonetic nature of 'voiced aspirates' in modern Indo-Aryan languages (we note Yadav 1984 and Dixit 1987, for instance), and a considerable literature that has built productively on the assumption that voiced and voiceless aspirates are phonetically similar in relevant ways (we note Ahmed \& Agrawal 1969, for instance, on perception confusion experiments with Hindi consonants in which the aspirates behave alike), though we acknowledge that the results have sometimes been contradictory as to the appropriateness of the traditional characterization of these sounds. For instance, Schiefer 1987, 1988 and Davis 1987 come to opposing conclusions as to whether or not the term 'aspiration' is appropriate in the description of these Hindi sounds, and this despite access to native speakers and state-of-the-art instrumentation that obviously is not available for the sounds of ancient Sanskrit. Although we do not claim to be anywhere close to settling the controversies surrounding the phonetics of these sounds, we 
lean towards considering the voiced and voiceless aspirates as being indeed phonetically similar as that matches their phonological behavior in Sanskrit, a domain in which we do have the relevant evidence. Still, by way of suggesting why a judgment of phonetic similarity might be called for, we add here spectrograms (provided through the courtesy of Dr. Shyam Agrawal of CEERI, in India, when he was a visitor at Ohio State University in 1987), of Hindi / $t$ th $d \mathrm{dh} /$, as they invite the interpretation of that each so-called aspirate indeed show similar period of 'glottal noise ... following the release of oral closure' (as Dixit 1987 describes the situation): 
${ }^{15}$ More generally, there is deaspiration before any obstruent, as Sanskrit has no clusters of the type $\left[\mathrm{g}^{\mathrm{h}} \mathrm{d}\right]$ or $\left[\mathrm{k}^{\mathrm{h}} \mathrm{t}\right]$ or $\left[\mathrm{k}^{\mathrm{h}} \mathrm{s}\right]$ or the like. The reasons are varied but are to be sought (at least in part) in the diachrony that such clusters could have had. For instance, clusters with a voiced aspirate as leftmost member would have triggered the progressive assimilation of Bartholomae's Law (thus giving $\left[\mathrm{g}^{\mathrm{h}} \mathrm{d}^{\mathrm{h}}\right]$ and ultimately $\left[\mathrm{gd}^{\mathrm{h}}\right]$ ). Voiceless aspirates derive, historically speaking, primarily from combinations of voiceless unaspirated stops with a Proto-Indo-European 'laryngeal' consonant (usually symbolized as ${ }^{*} \mathrm{H}$, but with no intended phonetic interpretation), especially the so-called 'second' or 'a-coloring' laryngeal; between consonants (thus, in clusters of, e.g. *-kHt-), these laryngeal consonants ultimately yielded (though most likely not directly so) a vowel ( $i$ in Indo-Iranian), so that $*_{\mathrm{kHt}}$ clusters would have given *kit, and thus no consonant cluster. There are a few relevant forms - e.g, the Atharva Vedic 3SG present form $\mathrm{gr} \geq \mathrm{n} \geq \mathrm{atti}$ '(s)he ties',

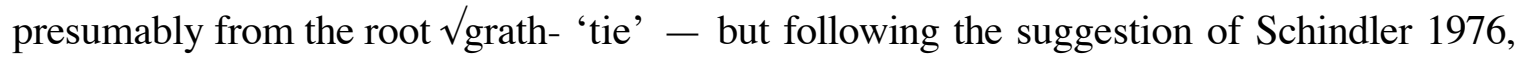
we ignore it, even though it apparently shows root-final deaspiration (without throwback). Schindler feels that, since it is a nonce-form, unparalleled in the paradigm of this verb, it is likely to have been modelled on the form $\underline{\mathrm{kr} \geq \mathrm{n} \geq \mathrm{atti}}$ '(s)he spins', from the semantically related root $\sqrt{ }$ krt-. See Schindler 1976 for further discussion.

${ }^{16}$ If a voiceless aspirate is preceded by an unaspirated voiced stop (e.g., in a sequence $/-\mathrm{g}+$ th-/ , the relevant assimilation rule in Sanskrit would be regressive, and so would yield [kth] as the outcome.

${ }^{17}$ Bartholomae's Law applied through/across $-s$ - in these clusters, and the $-s$ - was later deleted; see Schindler 1976 for discussion.

${ }^{18}$ That is to say, the present stem pr $\geq$ ccha- derives from Proto-Indo-European *pr $\geq \mathrm{k}$ 'sk'e-, with *-sk'e- as present-stem formative (found also in gaccha-, from * $\mathrm{g}^{\mathrm{w}} \mathrm{m} \geq$-sk'e-, 


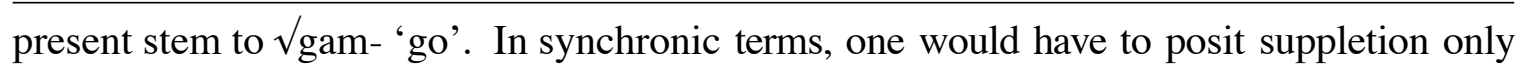
in root forms from which grammatical stems are built, e.g. $\sqrt{ }$ pr $\geq \mathrm{cch}$ - for the present and $\sqrt{ }$ prasv- for the future.

${ }^{19}$ Here, we again are ignoring $\mathrm{AV}$ gr $\geq \mathrm{n} \geq \mathrm{atti}$ - see footnote 15 .

${ }^{20}$ There actually are two other forms of $\sqrt{ } \mathrm{tr} \geq \mathrm{h}$ - besides the future that are relevant here: the

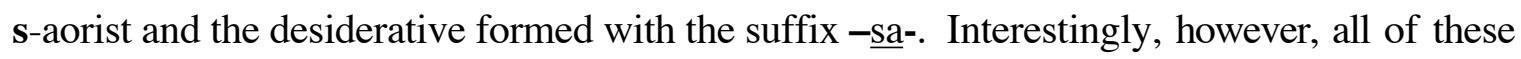
forms are ones that are not directly attested in texts but instead are cited by native grammarians (who sometimes constructed forms to fill out paradigms). One way of interpreting such forms with a root shape tark- is that, for the grammarians, this root simply was not on the list of aspiration throwback roots, just as in a similar way, the root they created for gutsa-, namely $\sqrt{ }$ gudh, was not on the list and thus occasioned no aspiration throwback. Similar considerations hold for $\sqrt{ }$ krudh- 'be angry', for which the grammarians give forms with a deaspirated final such as future stem krotsya-; it too would not have been 'on the list' of aspiration throwback forms.

${ }^{21}$ This is essentially the way that Schindler 1976 deals with occasional nonce forms in which aspiration throwback does not occur (e.g., Vedic nominative singular mitradruk 'hostile to Mitra', versus expected (and actually attested) mitradhruk, from the root $\sqrt{ }$ druh'be hostile'). That is, Schindler argues that such examples show the sporadic effects of analogical influence from forms, elsewhere in the paradigm which lack initial aspiration, i.e., in cases where no deaspiration of the root-final stop would occur, such as the genitive singular - druh-as.

22 The fact that these forms are onomatopoetic and/or expressive does not vitiate their value in showing that spellings with doubled aspirates were available, presumably when the phonetics actually warranted such a graphic representation. 
${ }^{23}$ Many thanks to Hans Henrich Hock for bringing this form and the syllabification evidence to our attention. These facts about the syllabification of forms such as budhna- are also fatal for the analysis given in Broe 1991, which crucially depends on the counterfactual assumption that aspiration is not licensed in syllable codas.

${ }^{24} \mathrm{~K} \& \mathrm{~L}$ were presumably working from the assumption that, since $\mathrm{DhN}$ - could occur in word-initial position - e.g. ghnanti 'they strike' - then such a sequence must always be syllable-initial. However, as noted above, the prátisvákhyas are quite clear about the syllabification of medial clusters in Sanskrit.

25 This observation and argument is due to Peter Lasersohn.

${ }^{26}$ The instrumental ending is considered in some treatments to behave like a separate word (hence the native grammatical tradition of calling these 'pada' endings - i.e. 'word' endings), even though it never occurs alone as a separate word. On such a view, the two contexts noted here would be collapsible as post-lexical, but only with a considerable degree of abstractness in the analysis.

27 The semantic parallel between this word and grapsa- is striking, and it may not be fortuitous if some sort of sound symbolism is responsible for linking at least the forms seen here with meanings that involve coalescence and a shared phonological pattern of STOP-(r)-V-STOP-sa-.

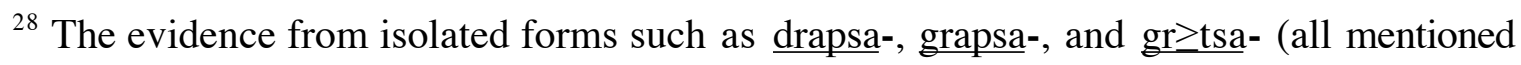
above in the text) shows that the absence of aspiration throwback when -s- was the deaspirating trigger was the original development, so that dhuks $\geq \mathbf{a}-$, with aspiration thrown back, is the innovative form (presumably analogically based on forms in which aspiration throwback was not linked to deaspiration before -s-). The limited but detectable productivity evinced by aspiration throwback in this context - within which aspiration 
spread to a small number of additional roots - need not be taken to indicate that the process is phonological in nature. As we argue more fully below, morphological rules in a process morphology approach can likewise show productivity of varying degrees.

${ }^{29}$ There is also the Vedic nonce-form dhak-tam (2DU.AOR.INJUNC.ACT of $\sqrt{ }$ dagh'reach'), which also shows aspiration throwback but displays exceptional behavior with regard to Bartholomae's Law (since one would expect **dagdham). We follow Schindler (1976: 635) in considering it to be modeled analogically on the 2SG.AOR.INJUNC.ACT form dhak, 'abetted by the occurrence of varktam in the same line [in the Rig Veda in which it occurs]'.

${ }^{30}$ On this approach to morphology, see Matthews 1972, Anderson 1982, 1992, Janda 1983, 1987, Beard 1995, and Stump 2001, among others.

${ }^{31}$ In this way, the aspiration throwback phenomenon constitutes what we have elsewhere called a '(morphological) constellation', i.e., a group of elements which share at least one characteristic property of form but are distinguished by individual idiosyncrasies (of either form or of function) that prevent their being collapsed with one another. See Janda \& Joseph 1986, 1988b, and 1999, and Joseph \& Janda 1988 for discussion and further examples.

${ }^{32}$ What we have in mind here is quite different from the approach of Golston 1996 (and even from its inverse); rather it is more in the direction of the non-morphemic, word-based approach to morphology advocated by Singh \& Agnihotri 1997.

${ }^{33}$ To be fair to the autosegmentalists - and as indicated by our own discussion of (16) and (17), with its reference to 'automatic phonology' - we readily admit that there can be some aspects of deaspiration phenomena in Sanskrit which are not a matter of morphology. As Hans Henrich Hock has reminded us (see also $\$ 2.2$ above and references there), deaspiration automatically takes place when a consonant is 'doubled' (geminated), e.g., after 
$\mathbf{r}$, as in /artha-/ 'goal' $\rightarrow$ [arttha-], /dírgha-/ 'long' $\rightarrow$ [díggha-]. Since the process in question is automatic and exceptionless, we see no conflict here between the deaspiration in gemination and the morphologically (even morpholexically) restricted deaspiration which remained in the aftermath of Grassmann's Law (for instance, in reduplication), or with another aspiration alternation - i.e., aspiration throwback - being morphological in nature. In Sanskrit, some aspects of the treatment of aspiration phenomena in general may indeed be automatic and thus better accounted for phonologically, but we submit that it is not the case that all such phenomena are best handled in that way. 